\title{
Food and values: an examination of values underlying attitudes toward genetically modified- and organically grown food products
}

Citation for published version (APA):

Dreezens, E. A. A., Martijn, C., Tenbült, P., Kok, G. J., \& de Vries, N. K. (2005). Food and values: an examination of values underlying attitudes toward genetically modified- and organically grown food products. Appetite, 44(1), 115-122. https://doi.org/10.1016/j.appet.2004.07.003

Document status and date:

Published: 01/01/2005

DOI:

10.1016/j.appet.2004.07.003

Document Version:

Publisher's PDF, also known as Version of record

\section{Document license:}

Taverne

Please check the document version of this publication:

- A submitted manuscript is the version of the article upon submission and before peer-review. There can be important differences between the submitted version and the official published version of record.

People interested in the research are advised to contact the author for the final version of the publication, or visit the DOI to the publisher's website.

- The final author version and the galley proof are versions of the publication after peer review.

- The final published version features the final layout of the paper including the volume, issue and page numbers.

Link to publication

\footnotetext{
General rights rights.

- You may freely distribute the URL identifying the publication in the public portal. please follow below link for the End User Agreement:

www.umlib.nl/taverne-license

Take down policy

If you believe that this document breaches copyright please contact us at:

repository@maastrichtuniversity.nl

providing details and we will investigate your claim.
}

Copyright and moral rights for the publications made accessible in the public portal are retained by the authors and/or other copyright owners and it is a condition of accessing publications that users recognise and abide by the legal requirements associated with these

- Users may download and print one copy of any publication from the public portal for the purpose of private study or research.

- You may not further distribute the material or use it for any profit-making activity or commercial gain

If the publication is distributed under the terms of Article $25 \mathrm{fa}$ of the Dutch Copyright Act, indicated by the "Taverne" license above, 


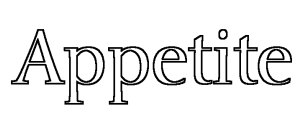

Appetite 44 (2005) 115-122

www.elsevier.com/locate/appet

Research Report

\title{
Food and values: an examination of values underlying attitudes toward genetically modified- and organically grown food products
}

\author{
Ellen Dreezens ${ }^{\mathrm{a}, *}$, Carolien Martijn ${ }^{\mathrm{a}}$, Petra Tenbült ${ }^{\mathrm{b}}$, Gerjo Kok ${ }^{\mathrm{a}}$, Nanne K. de Vries ${ }^{\mathrm{b}}$ \\ a Department of Experimental Psychology, Faculty of Psychology, Maastricht University, P.O. Box 616, 6200 MD Maastricht, The Netherlands \\ ${ }^{\mathrm{b}}$ Department of Health Education and Promotion, Faculty of Health Sciences, Maastricht University, Maastricht, The Netherlands
}

Received 29 January 2003; accepted 16 July 2004

\begin{abstract}
This study addresses which specific values play a role in predicting participants' attitudes toward genetically modified food (GMF) and organically grown food (OGF). The first central question is whether the attitudes towards GMF and OGF are influenced by specific values and beliefs. The second central question is whether the attitudes towards GMF and OGF are related to each other, and whether the specific values underlying these two attitudes are also related to each other. A total of 100 participants responded to the Schwartz Value Survey and two questionnaires about GMF and organically grown food. When respondents scored high on the value power (dominance, submission), they rated GMF positively and OGF more negatively. Respondents who rated the value universalism (welfare for all people and protection of nature) high, rated OGF as positive. Furthermore, the relationship between attitudes and values was mediated by beliefs. These findings imply a meaningful relationship between specific values, beliefs, and these food-related attitudes, and suggest that values might play a role in explaining attitudes toward GMF and OGF products.
\end{abstract}

(C) 2004 Elsevier Ltd. All rights reserved.

Keywords: Genetically modified foods; Organic foods; Attitudes, beliefs and values; Schwartz value survey

Although taste, prize, availability and nutrition value are important factors, some people decide what, or what not to eat on the basis of moral considerations. For example, in the past few years, consumers have been confronted with television images of thousands of animal corpses that were 'preventively' slaughtered to stop the spread of epidemics such as swine fever and foot-and-mouth disease. Although most of these animal diseases do not affect human health, some people banned meat partly or completely from their diet or decided to buy only organic meat because the way animals were treated in bio-industry contravened their principles of animal welfare. This paper examines what moral considerations underlie people's choices for certain food types.

The interest for food-related issues seems to be growing. Shanahan, Scheufele, and Lee (2001) for example, report an increase in media coverage of food related topics. Moreover, in reaction to recent outbreaks of BSE and

\footnotetext{
* Corresponding author.

E-mail address: e.dreezens@ psychology.unimaas.nl (E. Dreezens).
}

hormone scandals, people have become more aware of the food they are eating (Kirk, Greenwood, Cade, \& Pearman, 2002; Kubberød, Ueland, Tronstad, \& Risvik, 2002). Dieting styles like vegetarianism, veganism and organically grown foods have become more common. Recent studies have shown that the number of vegetarians has grown in several countries over the last few years (Allen \& Baines, 2002; Kirk et al.; Kubberød et al.; Lea \& Worsley, 2001; Povey, Wellens, \& Conner, 2001).

Povey et al. (2001) found that norms and values play an important role in the decision to adopt a vegetarian or vegan diet. Both vegetarians and vegans report health related, humanitarian and environmental reasons for their diets. On the other hand, they consider the eating of meat barbaric, environment unfriendly, and unhealthy. Therefore, it seems that environmental values as well as humanitarian values play a central role in deciding to adopt a certain dietary style.

In this article we report a study that explored whether people's attitudes towards food products are related to the basic human values they adhere to in life. We focused on 
two types of food products: genetically modified food (GMF) and organically grown food (OGF). The choice for these two types of products was made because of their presumed incompatibility. It seems likely that attitudes towards OGF and GMF are negatively related because the most central features of OGF are 'naturalness' and 'pureness' (Schifferstein \& Oude Ophuis, 1998) whereas GMF is manipulated and altered by human hands. Therefore, it seems unlikely that a positive attitude towards OGF co-occurs with a positive GMF-attitude. The selection of two presumably irreconcilable food-issues enabled us to study whether specific attitude positions are linked to specific patterns of values. Thus, our first question was whether attitude positions (e.g. a positive OGF attitude or a negative GMF attitude) are influenced by specific values and beliefs. Our second question was whether specific combinations of attitude positions (e.g. a positive OGF attitude and a negative GMF attitude) are reflected in specific combinations of values.

Until now, most studies focused on revealing the underlying value-attitude structure within one production technology, for example organic beer versus organic bread (Grankvist \& Biel, 2001; Grunert \& Juhl, 1995; Magnusson, Arvola, Hursti, Åberg, \& Sjödén, 2003) or genetically modified beer versus genetically modified bread (Bredahl, 1999; Bredahl, 2001; Magnusson \& Husti, 2002; Pfister, Böhm, \& Jungermann, 2000). However, as far as we know, none of these studies compared attitudes and their underlying values between distinct production technologies that represent two possibly contrasting food-issues.

\section{Genetically modified food and organically grown food}

Genetic modification is the change of hereditary material by placing properties of one organism (micro-organism, plant, or animal) into another organism (Hautvast \& van de Wiel, 2001). Using this technique, plant varieties can be created that are, for instance, richer in vitamins, lower in fat, resistant against herbicides and diseases, or that grow faster (Niaba, 2001). Genetically modified ingredients can be found in a large number of products like cookies, chocolate, sauces and cheese. Furthermore, a great number of fruits and vegetables currently available in our supermarkets, like soy and maize, have been genetically modified. Probably all of us have consumed GMF at least once, with or without knowing so.

OGF is produced without the use of synthetic chemicals, such as pesticides and fertilizers and is, by definition, not genetically modified. Furthermore, livestock is not treated preventively with medication in order to avoid diseases. Therefore, organic end products are unlikely to contain residues of those chemicals (Schifferstein \& Oude Ophuis, 1998).

\section{Attitudes and values}

An attitude is a psychological tendency that is expressed by evaluating a particular entity with some degree of favor or disfavor (Eagly \& Chaiken, 1995). The internal structure of attitudes consists of mental representations of these evaluative responses. These responses can be based upon feelings, cognitions or prior experience. Values and beliefs are thought to be the building blocks of attitudes (Eagly \& Chaiken, 1995; Verplanken \& Holland, 2002). Values can be seen as the most abstract cognitions or extreme global attitudes, as goals to provide general orientation and organization for life (Austin \& Vancouver, 1996), and they serve, as Rokeach (1968) puts it, as 'standards' or models for attitudes, beliefs and behavior. Values, attitudes, and beliefs form a hierarchical structure with values higher in the hierarchy (general level) and beliefs and attitudes at the base (specific level). The entire set of cognitive, affective and behavioral responses, together with values and beliefs within an attitude, constitutes the intra-attitudinal structure.

Attitudes are not only linked to values and beliefs, but also to each other. This is called an inter-attitudinal structure and it can encompass a large number of attitudes. An example of how a person feels towards an issue such as 'dog races' is probably related to his or her opinion on 'circus acts with animals' and 'equal rights for man and animals'. Thus, people who loath dog races probably also disapprove of elephants doing a handstand. The binding element between these different attitudes may be one and the same underlying value, such as 'equality for all living creatures' or 'protection of nature and wildlife'. A taxonomy of values that proved to be relatively stable across cultures was developed by Schwartz (Schwartz, 1992; Schwartz \& Bilsky, 1990). According to this taxonomy, there are ten motivational value types that can be found in every culture. These motivational value types range from security to hedonism and from achievement to conformity. In the Schwartz Value Survey (Schwartz, 1992), that was designed to measure the importance attached to values, each of the ten motivational values types consists of a number of subdivisions or more specific values. In Table 1, the ten motivational value types and their underlying specific values are presented.

Several researchers have shown a value-attitude-behavior relationship (Bernard, Maio, \& Olson, 2003; Homer \& Kahle, 1988; Luzar \& Cosse, 1998; Maio \& Olson, 1994; Stienstra, Ruelle, \& Bartels, 2002; Thøgersen \& Ölander, 2002). It is commonly believed that the causality flows from values through attitudes to behavior, and not the other way around. This means that values have an impact on attitudes, which in turn influence people's behavior. Values are generally understood as extremely stable constructs that are not easily changed, even if considerable effort is invested.

Values affect attitudes by focusing not simply on the whole attitude, but by making some specific aspects of 
Table 1

Definitions of motivational value types in terms of their goals and the sub-values that represent them

\begin{tabular}{|c|c|}
\hline Value & Motivational value types (and sub values) \\
\hline Self direction & $\begin{array}{l}\text { Independent thought and action, choosing, creating, exploring (freedom, creativity, independent, choosing own } \\
\text { goals, curious, self-respect) }\end{array}$ \\
\hline Stimulation & Excitement, novelty and challenge in life (an exciting life, a varied life, daring) \\
\hline Hedonism & Pleasure and sensuous gratification for oneself (pleasure, enjoying life) \\
\hline Achievement & $\begin{array}{l}\text { Personal success through demonstrating competence according to social standards (ambitious, influential, capable, } \\
\text { successful, intelligent, self-respect) }\end{array}$ \\
\hline Power & $\begin{array}{l}\text { Social status and prestige, control and dominance over people and resources (social power, wealth, authority, } \\
\text { preserving my public image, social recognition) }\end{array}$ \\
\hline Security & $\begin{array}{l}\text { Safety, harmony and stability of society, of relationships and of self (national security, reciprocation of favors, } \\
\text { family security, sense of belonging, social order, healthy, clean) }\end{array}$ \\
\hline Conformity & $\begin{array}{l}\text { Restraint of actions, inclinations and impulses likely to upset or harm others and violate social expectations or } \\
\text { norms (obedient, self-discipline, politeness, honoring of parents and elders) }\end{array}$ \\
\hline Tradition & $\begin{array}{l}\text { Respect, commitment and acceptance of the customs and ideas that traditional culture or religion provide the self } \\
\text { (respect for tradition, devout, accepting my portion in life, humble, moderate) }\end{array}$ \\
\hline Benevolence & $\begin{array}{l}\text { Preservation and enhancement of the welfare of people with whom one is in frequent personal contact (helpful, } \\
\text { responsible, forgiving, honest, loyal, mature love, true friendship) }\end{array}$ \\
\hline Universalism & $\begin{array}{l}\text { Understanding, appreciation, tolerance and protection for all people and for nature (equality, unity with nature, } \\
\text { wisdom, a world of beauty, social justice, broad-minded, protecting the environment, a world at peace) }\end{array}$ \\
\hline
\end{tabular}

Adapted from the Schwartz Value Survey (Schwartz \& Sagie, 2000).

an attitude more salient or important. For example, imagine a person who holds the following beliefs about glass recycling: 'recycling glass saves natural resources' and 'recycling glass takes time and effort'. If this person considers the value universalism (protection for all people and for nature) as a guiding principle in his or her life, the first belief is probably more important and salient to this person than the second belief. Because of the match between this person's value and a specific belief, such a belief is likely to influence a person's overall attitude towards glass-recycling to a greater extent than beliefs that do not match. Vice versa, if a person considers hedonism (pleasure, enjoying life) as a guiding principle in life, the belief about the (immaterial) costs of glass recycling will probably influence the attitude most.

It is important to note that values influence attitudes only under certain conditions. Only those values that are related to an attitude, that are part of a person's self concept, and that are activated within a specific behavioral context have an impact on attitudes. In a series of studies, Verplanken and Holland (2002) showed that the activation of specific values could change attitudes and choice behavior. In one of their studies, environment-related values were activated through a priming procedure. This procedure consisted of presenting participants with 20 values, and asking them to form an impression of a person who adheres to these values. In the priming condition, 12 of these 20 values were related to the environment, whereas in the control condition, they were all unrelated to the environment. These activated values directed attention to value-relevant information (information about the environment) and heightened the weight of value-relevant attributes. Participants in the priming condition of their study chose television sets that scored higher on environment-aspects than participants in the control condition, but only when environment related values were part of the person's self concept.

\section{The present research}

In this article, we report a study in which we examined which values underlie attitudes towards GMF and OGF products. We focused on GMF versus OGF products because these are both relatively recent, but presumably opposing developments. Values could be a useful tool in predicting or explaining peoples' attitudes towards issues like GMF and OGF.

Previous research has already shown some relations between specific values and food-related attitudes. Povey et al. (2001) found that environmental- and humanitarian values play an important role in the decision to adopt a vegetarian or vegan diet. Thøgersen and Ölander (2002) have shown that there is a predominant causal influence between values like universalism (welfare for all people and protection of nature) and benevolence (welfare of close others) and environment-friendly attitudes and behavior. Homer and Kahle (1988) showed that values like hedonism (pleasure or sensuous gratification for oneself) and stimulation (need for variety and stimulation) had an effect on attitudes towards nutrition. Other researchers (Grankvist \& Biel, 2001; Grobe, Douthitt, \& Zepeda, 1999; Grunert \& Juhl, 1995; Schifferstein \& Oude Ophuis, 1998), have also shown that values like spirituality (meaning and inner harmony), benevolence and universalism have a positive relation to environmental attitudes. We predict that the attitude towards OGF will be predicted by similar values. As we assume that GMF opposes OGF, values that are opposed 
to universalism and benevolence, such as achievement and power, are expected to be related to GMF.

With findings like these in mind, we propose the possibility that specific values underlie attitudes towards GMF and OGF. The central questions of this study are based on the idea of the existence of an intra-attitudinal structure and an inter-attitudinal structure (Eagly \& Chaiken, 1995). The first question is whether the attitudes towards GMF and OGF are influenced by specific values and beliefs. Because, theoretically, beliefs are positioned between values and attitudes, the possibility was raised that beliefs might mediate the relationship between attitudes and values. The second question is whether specific combinations of attitude positions are reflected in specific combinations of values.

\section{Method}

\section{Participants}

A total of one hundred students of the University of Maastricht took part in our study and received a monetary reward for their participation. The mean age of the participants was 20.2 years $(\mathrm{SD}=3.50$, ranging from 18 to 50$)$.

\section{Procedure}

Participants were invited to the laboratory. After explaining the procedure and the purpose of the survey, each participant was seated behind a computer. A computercontrolled program was used to generate the questionnaires. Participants first filled out the Schwartz Value Survey (SVS). The values were shown on the computer screen and consisted of catchwords (e.g. 'equality'), followed by a brief extension (e.g. 'equal chances for everybody'). When respondents finished the SVS, the computer program automatically started the questionnaires about GMF and OGF. When the participants finished filling out the questionnaires, they were debriefed, thanked and paid.

\section{Measures}

The following measures were taken:

(i) Schwartz Value Survey. The Dutch version of this survey (Schwartz \& Huismans, 1995) consists of ten motivational value types (like 'tradition'), which are tested by asking people to rate how important they find 58 sub-values (like 'respect for tradition' and 'humble') (see also Table 1). Participants were asked to rate to what extent each of these 58 sub-values is a guiding principle in their lives on a 9-point scale ranging from 1 (opposite to my values) to 7 (extremely important). Reliability analyses showed that the alpha values of the ten motivational value types ranged between 0.51 (tradition) and 0.87 (stimulation). The scores of the sub-values belonging to one motivational value type were averaged to create one single score per motivational value type (for the original phrasing, see Table 1).

(ii) Attitudes. Four items were used to assess participants' attitudes towards GMF and the same four items measured attitudes toward OGF. Participants were asked to rate 'what do you generally think about GMF/OGF' on four 5-point scales varying from 1 (very unpleasant / very bad / very unfavorable / very negative) to 5 (very pleasant / very good / very favorable / very positive). Reliability analyses showed that the alpha values of this scale were 0.90 for both GMF and OGF. The mean of the four GMF-attitude items was computed to construct one index measuring the attitude towards GMF. A low index-score indicated a negative attitude towards GMF, a high index score a positive attitude towards GMF. An attitude index towards OGF was created in a similar manner.

(iii) Beliefs. The beliefs that were used for the purpose of this study were derived from a pilot study. This study consisted of 20 interviews, taken from people of different ages and professions (students, farmers etc., with a mean age of 24.39 SD $=8.44$ ). Participants were asked questions like 'do you know what genetic modification/organical production is', 'which associations do you have with GMF/OGF' and 'what do you think are the advantages and disadvantages of GMF/OGF'. Participants' answers were recorded and categorized and served as input for constructing the beliefs used in this study. Participants in the present study were asked to rate whether they disagreed or agreed with a number of beliefs (on a 5-point scale, varying from 1 (disagree very much to) 5 (agree very mисh). For GMF the beliefs that were used were: 'by making use of GMF our food can be improved', 'GMF offers us interesting possibilities', 'GMF is unnatural', 'developing countries will be disadvantaged by GMF', 'GMF disturbs the ecological balance', 'GMF products are less healthy than not GMF products', 'GMF production leads to more food allergies', 'GMF could lead to problems on the long term which we cannot see right now' and 'GMF is good for the environment'. A reliability analysis showed that the alpha value of these nine beliefs was 0.76 . A belief index was created by averaging the 9 belief items. A low index score indicated an overall negative belief score for GMF. For OGF the beliefs that were used were: 'OGF is good for the environment', 'OGF tastes good', 'OGF products are less healthy than not OGF products', 'OGF products are of lesser quality', 'OGF is unnatural', 'OGF production leads to unforeseen consequences for humans and animals', and 'there are risks attached 
to OGF production'. The alpha value of these seven beliefs was 0.72 . A belief index was created by averaging the seven belief items. A low index score indicated an overall negative belief score for OGF.

\section{Results}

\section{Intra-attitudinal structure}

To analyze which values were related to attitudes towards GMF and OGF, two regression analyses were conducted. The predictors in both analyses were the ten motivational value types. In the first analysis, only the value power added significantly to the prediction of the GMF attitude $(\beta=0.32, p<0.05)$. In the second analysis, only universalism added significantly to the prediction of the OGF attitude $(\beta=0.28, p<0.05)$.

Part of our first research question was to what extent beliefs towards GMF mediated the influence of power on attitudes towards GMF. A mediation analysis (Baron \& Kenny, 1986) confirmed that power had a positive effect on attitudes toward GMF, but this effect was mediated by beliefs towards GMF. First, attitudes towards GMF were regressed on power $\left(R^{2}=0.09\right)$. Power showed to be a significant predictor of attitudes toward GMF $(\beta=0.29$, $p<0.01), F(1,98)=9.22, p<0.01$. Second, beliefs towards GMF were regressed on power. Power was a significant predictor of the beliefs towards GMF $(\beta=0.28, p<0.01)$, $F(1,98)=8.42, p<0.01$. Finally, attitudes towards GMF were regressed on power and on beliefs towards GMF $\left(R^{2}=0.39\right)$. The effect of the beliefs towards GMF on the attitude toward GMF $(\beta=0.61, p<0.01)$ resulted in the disappearance of the effect of power on the attitude towards GMF $(\beta=0.13, n s), F(2,97)=30.52, p<0.01$.
Therefore, the relationship between the attitude towards GMF and power seemed to be completely mediated by the beliefs towards GMF.

A second mediation analysis was conducted to see if the effect of universalism on attitudes towards OGF was mediated by beliefs towards OGF. First, attitudes towards OGF were regressed on universalism $\left(R^{2}=0.08\right)$. Universalism showed to be a significant predictor of attitudes towards OGF $(\beta=0.29, p<0.01), F(1,97)=8.84, p<0.01$. Second, beliefs towards OGF were regressed on universalism. Universalism was a significant predictor of the beliefs towards OGF $(\beta=0.22, p<0.05), F(1,98)=4.80, p<0.05$. Finally, attitudes towards OGF were regressed on universalism and on beliefs towards OGF $\left(R^{2}=0.43\right)$. The effect of the beliefs towards OGF on the attitude towards OGF $(\beta=0.60, p<0.01)$ resulted in a weakened effect of universalism on the attitude towards OGF $(\beta=0.16$, $p=0.05), F(2,96)=35.53, p<0.01$. A Sobel test, which tests the null hypothesis that the route from values via beliefs to attitudes differs from zero, confirmed this partial mediation, $F(2,96)=2.14, p<0.05$ (Kenny, Kashy, \& Bolger, 1998). These results suggest that the attitude towards OGF is positively influenced by universalism and that the attitude towards GMF is positively influenced by power. These relationships between attitudes and values are mediated by beliefs and are summarized in Fig. 1 .

An additional analysis was conducted to see if participants who are opponents or proponents of GMF or OGF, show a different pattern in the values they adhere to. First, all participants were divided into an anti GMF group or pro GMF group (using the scale midpoint of the attitude index). Then, two separate ANOVA's were conducted. The first used power as a dependent variable (and pro versus anti GMF as independent variable); the second treated universalism as a dependent variable (and pro versus anti GMF as independent variable). The results of these analyses
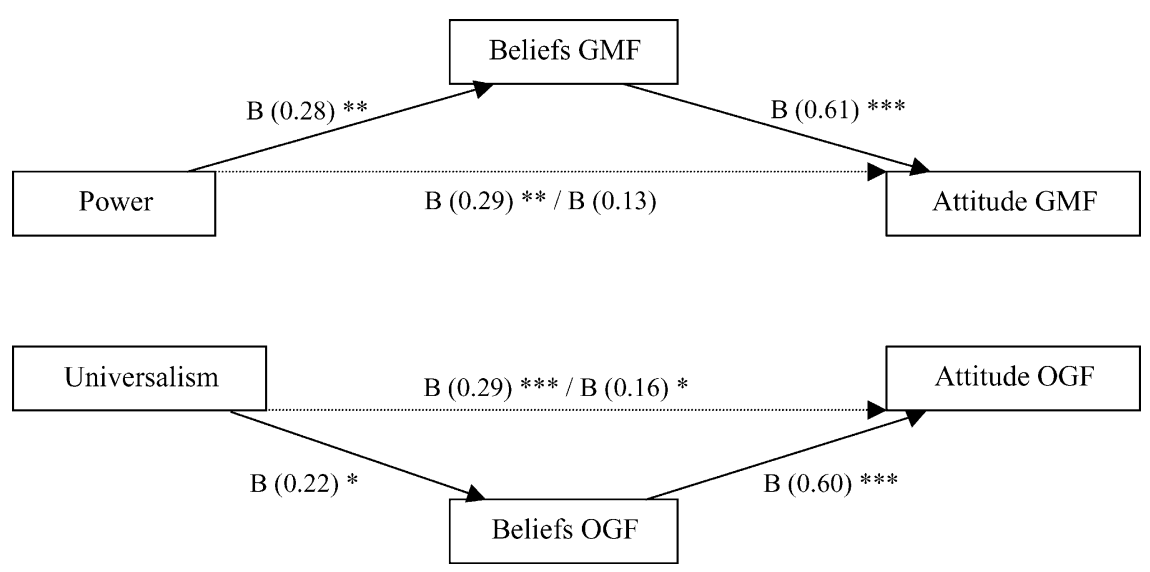

Fig. 1. Intra-attitudinal structure. Note. The top part shows the relationship between power, beliefs towards genetically modified food (GMF) and attitudes toward GMF. The lower part shows the relationship between universalism, attitudes towards organically grown food (OGF) and attitudes toward OGF. The first numbers corresponding to the arrow between the value and the attitude is the regression coefficient from the regression of attitudes on values. The second number is the regression coefficient from the regression of attitudes on values, corrected for the effect of beliefs on attitudes. $* p<0.05$. $* * p<0.01$. $* * * p<0.001$. 
Table 2

The values that opponents and proponents of GMF and OGF adhere to

\begin{tabular}{lllll}
\hline & GMF pro & GMF con & $F$ & $p$ \\
\hline Universalism & 4.00 & 4.17 & 0.77 & 0.38 \\
Power & 2.36 & 1.61 & 9.50 & $0.003 * *$ \\
\hline & OGF pro & OGF con & $F$ & $p$ \\
\hline Universalism & 4.17 & 3.92 & 1.25 & 0.27 \\
Power & 1.71 & 2.40 & 5.29 & $0.024 *$ \\
$* p<0.05, * * p<0.01$. & & &
\end{tabular}

showed that participants who were anti GMF, scored lower on the value power than the participants who were pro GMF, $F(1,98)=9.50, p<0.01$. However, participants who scored low on GMF, did not differ in their universalism scores from participants who scored high on GMF, $F(1,98)=0.77, p=$ ns.

Second, participants were divided into an anti OGF group or a pro OGF group (using the midpoint of the attitude index). Then, two ANOVA's were conducted. The first had power as a dependent variable (and pro versus anti OGF as an independent variable) and the second had universalism as a dependent variable (and pro versus anti OGF as an independent variable). The results of these analyses showed that participants who scored low on OGF, scored higher on the value power than the participants who scored high on OGF, $F(1,98)=5.29, p<0.05$. However, participants who scored low on OGF, did not differ in their universalism scores from participants who scored high on OGF, $F(1,98)=1.25, p=$ ns. In summary, people who score high on GMF or OGF differ in how much they adhere to the value power from people who score low on GMF or OGF. These results can be found in Table 2 .

\section{Inter-attitudinal structure}

A correlational analysis was conducted to find out whether specific relationships between the attitude towards OGF and GMF, and the values related to these two attitudes existed. Both the attitudes towards OGF and GMF and the values power and universalism were inserted into this analysis. It was shown that the attitudes towards OGF and GMF were negatively correlated, $r(98)=-0.29, p<0.01$. Power was positively correlated with attitudes toward GMF, $r(98)=0.29, p<0.01$ and universalism was positively correlated with attitudes towards OGF, $r(98)=0.29$, $p<0.01$, which confirmed the results of the regression analysis. Furthermore, power was negatively correlated with the attitude toward OGF, $r(98)=-0.24, p<0.05$. These results propose an inter-attitudinal structure in which the two attitudes are opposed to each other. Furthermore, specific combinations of attitude patterns are reflected in specific combinations of values. The results of the interattitudinal structure are summarized in Fig. 2.

\section{Discussion}

In this study, we examined the underlying inter- and intra-attitudinal structures of two, supposedly opposing attitude issues, i.e. GMF and OGF. A first finding was that the attitudes towards GMF and OGF were indeed negatively related. Apparently, a positive attitude towards GMF implies a negative attitude towards OGF and vice versa.

Furthermore, it was shown that OGF was related to power (negatively) as well as universalism (positively), and GMF was related to the value power (positively). This implies that the two opposing attitude positions indeed have a connection with distinctly different values, as was predicted. Respondents who agree with human domination over our natural environment, or are not against having everything under control, are also not opposed to influencing natural processes. These respondents also foster the least negative feelings towards GMF, because GMF is the ultimate way for human beings to master natural processes that they could not master in the past. A high adherence to OGF, which stands for naturalness and unaffectedness, is not in line with the value power. The essence of OGF is that in its production, human interventions are sparse and as natural as possible. Therefore, respondents being in favor of OGF show a low adherence to the value power. Although we expected the reverse relationship between GMF attitudes and the value universalism, this was not the case for our group of respondents. The value universalism could not differentiate between the respondents who scored high or low on GMF.

These results are in accordance with the predictions on the basis of the Schwartz value structure. According to this structure, the values power and universalism are two extremes on a continuum that ranges from selftranscendence (promote welfare of others) to

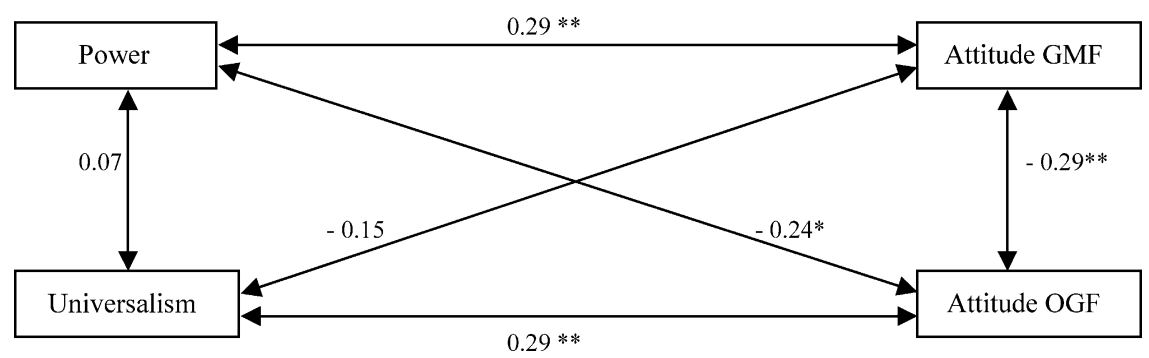

Fig. 2. Inter-attitudinal structure. Note. The numbers represent the correlations between the concepts. ${ }^{*} p<0.05 .{ }^{* *} p<0.01$. 
self-enhancement (own personal interests), which implies that the two values are in conflict with each other. A possible practical implication of these findings is that, at least for OGF, there could be two ways to affect attitudes. On the one hand, one could focus on universalism, by emphasizing that OGF fits entirely into a universalistic state of mind. On the other hand, one could also try to focus on power, by showing that being opposed to power is compatible with a pro OGF attitude.

One criticism of these results could be that the values power and universalism accounted for only around $10 \%$ of the variation in attitudes. One of the most important reasons for this is that values are not the only concepts that influence and form attitudes. Other researchers have suggested that a large number of other concepts like emotions (Giner-Sorolla, 1999) and past behavior (Albarracín \& Wyer, 2000) also have an effect on attitudes. However, this does not mean that values are not of interest in their relationship with attitudes. Another reason that values only accounted for a modest variation in attitudes may be because values and attitudes are not on the same level of generality. In their correspondence principle, Ajzen and Fishbein (1977) stated that substantial attitudebehavior correlations will be established only when both measures correspond in their level of specificity. Similarly, the level of specificity of the values and attitudes that were used in this study also differs, because values are per definition global constructs, whereas attitudes are much more specific. Given this difference in specificity, it is quite meaningful that we were able to establish modest, but significant relationships between values and attitudes.

A further goal of this study was to specify the position of beliefs and attitudes in their relationship with values. An interesting finding was that beliefs related to GMF and OGF moderated the relation between attitudes and values. Earlier studies have suggested such a relationship between values, attitudes and beliefs, but until now such relationship has not been explicitly demonstrated. The fact that beliefs are positioned between attitudes and values suggests that changing attitudes via values is probably more effective if the communication aims at the link between a person's values and relevant beliefs. However, it may be the case that this relationship mostly holds for attitude-issues for which people show a low involvement. In this case, beliefs, which are more specific than the more general attitudeissue, might help people to see the attitude-object in less abstract terms and therefore make it more down to earth and more understandable and applicable for respondents. This can result in a heightened involvement with the attitude-issue.

Of course it should be noted that the specific content of relations between attitude positions and values are based on a limited sample of Dutch university students. In other words, samples such as 'average consumers', 'conservationists' or 'technical engineers' could show a completely different attitude-value pattern. However, it was not our aim to obtain a general representation of how certain food-related attitudes relate to specific values but to demonstrate that values may add to our understanding of food-related attitude structures.

All in all, our results show that opposing attitude positions are reflected in a different structure of values. Identifying relevant values helps to understand food-related attitudes and, moreover, knowledge about specific underlying patterns of values may serve as input for developing instruments to affect or maintain existing attitudes. Therefore, research aiming at understanding or influencing food related attitudes should not limit itself to categorizing attitudes and their accompanying relevant beliefs, but should also focus on the specific underlying values.

\section{Acknowledgements}

This research was supported by a grant from ZonMw (014-12-001). The authors would like to thank Alard Roebroeck for his help with building the program that enabled us to collect all data electronically and for his comments on earlier drafts of this paper.

\section{References}

Ajzen, I., \& Fishbein, M. (1977). Attitude-behavior relations: A theoretical analysis and review of empirical research. Psychological Bulletin, 84, 888-918.

Albarracín, D., \& Wyer, R. S., Jr. (2000). The cognitive impact of past behavior: Influences on beliefs, attitudes and future behavioral decisions. Journal of Personality and Social Psychology, 79, 5-22.

Allen, M. W., \& Baines, S. (2002). Manipulating the symbolic meaning of meat to encourage greater acceptance of fruits and vegetables and less proclivity for red and white meat. Appetite, 38, 118-130.

Austin, J. T., \& Vancouver, J. B. (1996). Goal constructs in psychology: Structure, process, and content. Psychological Bulletin, 120, 338-375.

Baron, R. M., \& Kenny, D. A. (1986). The moderator-mediator variable distinction in social psychological research: Conceptual, strategic and statistical considerations. Journal of Personality and Social Psychology, 51, 1173-1182.

Bernard, M. M., Maio, G. R., \& Olson, J. M. (2003). The vulnerability of values to attack: Inoculation of values and value-relevant attitudes. Personality and Social Psychology Bulletin, 29, 63-75.

Bredahl, L. (1999). Consumers' cognitions with regard to genetically modified foods: Results of a qualitative study in four countries. Appetite, 33, 343-360.

Bredahl, L. (2001). Determinants of consumer attitudes and purchase intentions with regard to genetically modified foods: Results of a crossnational survey. Journal of Consumer Policy, 24, 23-61.

Eagly, A. H., \& Chaiken, S. (1995). Attitude strength, attitude structure and resistance to change. In R. E. Petty, \& J. A. Krosnick (Eds.), Attitude strength: Antecedents and consequences. Ohio State University series on attitudes and persuasion (Vol. 4). Hillsdag, NJ, US: Lawrence Erlbaum Associates, Inc.

Giner-Sorolla, R. (1999). Affect in attitude: Immediate and deliberative perspectives. In S. Chaiken, \& Y. Troope (Eds.), Dual-process theories in social psychology (pp. 441-461). New York, NY, US: Guilford Press. 
Grankvist, G., \& Biel, A. (2001). The importance of beliefs and purchase criteria in the choice of eco-labelled food products. Journal of Environmental Psychology, 21, 405-410.

Grobe, D., Douthitt, R., \& Zepeda, L. (1999). A model of consumers' risk perceptions toward recombinant bovine growth hormone (rbGH): The impact of risk characteristics. Risk Analysis, 19, 661-673.

Grunert, S. C., \& Juhl, H. J. (1995). Values, environmental attitudes and buying of organic foods. Journal of Economic Psychology, 16, 39-62.

Hautvast, J., \& van de Wiel, J. (2001). Biotechnologie en voedsel. [Biotechnology and food]. In Niaba (Ed.), Biotechnologie: Een plaats in de samenleving. [Brochure].

Homer, P. M., \& Kahle, L. R. (1988). A structural equation test of the value-attitude-behavior hierarchy. Journal of Personality and Social Psychology, 54, 638-646.

Kenny, D. A., Kashy, D. A., \& Bolger, N. (1998). Data analysis in social psychology. In D. T. Gilbert, S. T. Fiske, \& G. Lindzey (Eds.), The handbook of social psychology (Vol. 1), 4th ed. (pp. 223-265). New York: McGraw Hill.

Kirk, S. F., Greenwood, D., Cade, J. E., \& Pearman, A. D. (2002). Public perception of a range of potential food risks in the United Kingdom. Appetite, 38, 189-197.

Kubberød, E., Ueland, Ø., Tronstad, Å., \& Risvik, E. (2002). Attitudes towards meat and meat-eating among adolescents in Norway: A qualitative study. Appetite, 38, 53-62.

Lea, E., \& Worsley, A. (2001). Influences on meat consumption in Australia. Appetite, 36, 127-136.

Luzar, E. J., \& Cosse, K. J. (1998). Willingness to pay or intention to pay: The attitude-behavior relationship in contingent valuation. Journal of Socio-Economics, 27, 427-444.

Magnusson, M. K., Arvola, A., Hursti, U.-K., Åberg, L., \& Sjödén, P.-O. (2003). Choice of organic foods is related to perceived consequences for human health and to environmentally friendly behavior. Appetite, 40, 109-117.

Magnusson, M. K., \& Husti, U.-K. K. (2002). Consumer attitudes toward genetically modified foods. Appetite, 39, 9-24.

Maio, G. R., \& Olson, J. M. (1994). Value-attitude-behavior relations: The moderation role of attitude functions. British Journal of Social Psychology, 33, 301-312.
Niaba (2001). Toepassing biotechnologie waardevol voor de samenleving. [Application biotechnology valuable for society]. Report written under the jurisdiction of the Dutch Biotechnology Association.

Pfister, H. R., Böhm, G., \& Jungermann, H. (2000). The cognitive representation of genetic engineering: Knowledge and evaluations. New Genetics and Society, 19, 295-316.

Povey, R., Wellens, B., \& Conner, M. (2001). Attitudes towards following meat, vegetarian and vegan diets: An examination of the role of ambivalence. Appetite, 37, 15-26.

Rokeach, M. (1968). Beliefs, attitudes and values: A theory of organization and change. San Francisco, US: Jossey-Bass Inc., Publishers.

Schifferstein, H. N. J., \& Oude Ophuis, P. A. M. (1998). Health-related determinants of organic food consumption in The Netherlands. Food Quality and Preference, 9, 119-133.

Schwartz, S. H. (1992). Universals in the content and structure of values: Theoretical advances and empirical tests in 20 countries. In M. P. Zanna (Ed.), Advances in experimental social psychology (Vol. 25) (pp. 1-65). Waterloo: Academic Press, Inc.

Schwartz, S. H., \& Bilsky, W. (1990). Toward a theory of the universal content and structure of values: Extensions and cross-cultural replications. Journal of Personality and Social Psychology, 58, 878-891.

Schwartz, S. H., \& Huismans, S. (1995). Value priorities and religiosity in four Western religions. Social Psychology Quarterly, 58, 88-107.

Schwartz, S. H., \& Sagie, G. (2000). Value consensus and importance: A cross-national study. Journal of Cross-Cultural Psychology, 31, 465-497.

Shanahan, J., Scheufele, D., \& Lee, E. (2001). Attitudes about agricultural biotechnology and genetically modified organisms. Public Opinion Quarterly, 65, 267-281.

Stienstra, J., Ruelle, H., \& Bartels, G. (2002). A closer look at eleven years of environment perception through laddering. In G. Bartels, \& W. Nelissen (Eds.), Marketing for sustainability: Towards transactional policy-making. Amsterdam: IOS Press.

Thøgersen, J., \& Ölander, F. (2002). Human values and the emergence of a sustainable consumption pattern: A panel study. Journal of Economic Psychology, 23, 605-630.

Verplanken, B., \& Holland, R. W. (2002). Motivated decision making: Effects of activation and self-centrality of values on choices and behavior. Journal of Personality and Social Psychology, 82, 434-447. 